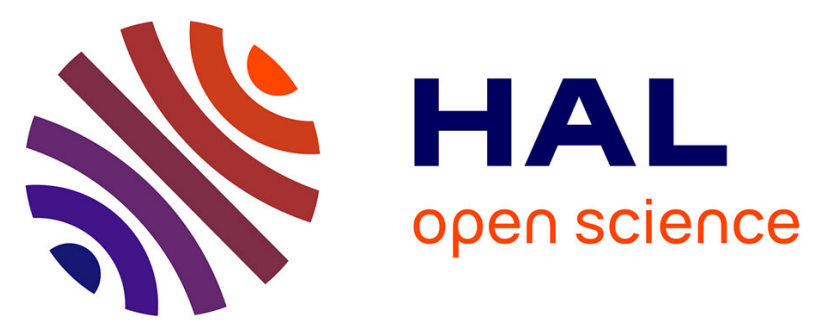

\title{
Introducing economic actors and their possibilities for action in LCA using sensitivity analysis: Application to hemp-based insulation products for building applications
}

Tristan Senga Kiessé, Anne Ventura, Hayo M.G. van Der Werf, Bogdan Cazacliu, Rachida Idir, Andy Andrianandraina

\section{To cite this version:}

Tristan Senga Kiessé, Anne Ventura, Hayo M.G. van Der Werf, Bogdan Cazacliu, Rachida Idir, et al.. Introducing economic actors and their possibilities for action in LCA using sensitivity analysis: Application to hemp-based insulation products for building applications. Journal of Cleaner Production, 2016, 142 (4), pp.3905-3916. 10.1016/j.jclepro.2016.10.069 . hal-01391748

\author{
HAL Id: hal-01391748 \\ https://hal.science/hal-01391748
}

Submitted on 13 Jul 2021

HAL is a multi-disciplinary open access archive for the deposit and dissemination of scientific research documents, whether they are published or not. The documents may come from teaching and research institutions in France or abroad, or from public or private research centers.
L'archive ouverte pluridisciplinaire HAL, est destinée au dépôt et à la diffusion de documents scientifiques de niveau recherche, publiés ou non, émanant des établissements d'enseignement et de recherche français ou étrangers, des laboratoires publics ou privés.

\section{다(1)(2)}

Distributed under a Creative Commons Attribution - ShareAlikel 4.0 International 


\title{
Introducing economic actors and their possibilities for action in LCA using sensitivity analysis: Application to hemp-based insulation products for building applications
}

\author{
Tristan Senga Kiessé a, c, *, Anne Ventura a , Hayo M.G. van der Werf ${ }^{\text {c }}$, Bogdan Cazacliu ${ }^{\text {b }}$, \\ Rachida Idir ${ }^{\mathrm{d}}$, Andrianandraina ${ }^{\mathrm{a}, \mathrm{b}}$ \\ a Civil Engineering and Eco-construction, UBL (Universite' Loire Bretagne), Universite' de Nantes, GeM Laboratory, France \\ ${ }^{\mathrm{b}}$ IFSTTAR - Nantes, Route de Bouaye CS4, 44344, Bouguenais Cedex, France \\ ' UMR SAS, INRA, AGROCAMPUS OUEST, 35000, Rennes, France \\ d Laboratoire 'eco-mat' eriaux, CEREMA, Ile de France, France
}

\begin{abstract}
The complexity of the Life Cycle Assessment (LCA) method requires many subjective choices throughout the procedure, which make decision making difficult and LCA results insecure. Our approach consists in combining life cycle thinking and sensitivity analysis to provide information to the actor of a foreground system within a product's life cycle. For any parameter of a foreground system, the trends and quantified influence on impact categories are systematically compared to determine the most effective action levers for actors controlling the process. This approach has been previously applied to a single actor, the farmer, in a case study of hemp crop production. In this study, we introduce a second life cycle actor: the industrial producer for transformation of hemp straw into insulation products for buildings. The relationships between farming and industrial actors are examined and demonstrate that industrial actors have action levers limited to climate change and energy consumption. Only a joint action of both actors can allow further reduction of climate change and energy consumption impacts. Nevertheless, the farmer action alone can allow reduction of other environmental impacts such as human toxicity or ecotoxicity.
\end{abstract}

\section{Introduction}

Life Cycle Assessment (LCA) can be used for different purposes. It can be used to take decisions at a variety of application levels ranging from public policy to specific product improvements within private companies. However, the link between LCA results and the subsequential decisions is not straightforward as shown by the extensive literature on the subject.

One of the main reasons for this difficulty is that LCA studies produce multiple outcomes because of the variety of environmental impacts considered. Thus many LCA users consider that LCA-based decisions consist first in deciding on priorities between indicators. According to Cowell et al. (2002) "LCA is based on the premise that trade-offs can be made between different

\footnotetext{
* Corresponding author. UMR SAS, INRA, AGROCAMPUS OUEST, 35000, Rennes France.

E-mail address: tristan.senga-kiesse@inra.fr (T. Senga Kiessé).
}

environmental impacts". Many other studies, based on the MultiAttribute Decision Analysis (MADA) have been conducted in that spirit. The first of them was a case study on an aluminium can (Miettinen and Hämäläinen, 1997). Most studies combining LCA and MADA focus on the impact assessment step of LCA. Thus, a generic frame meeting the requirements of the impact assessment step is proposed by Seppälä et al. (2001).

However, this approach requires that decision-makers express preferences on impact categories they barely understand. Furthermore, it implicitly assumes that Life Cycle Impact Assessment (LCIA) provides objective quantified results and that the subjective part of the decisions can be made once the results are obtained. In fact, LCA implies both objective and subjective choices all along the process itself. Beyond the subjective aspects of the LCIA indicators themselves, such as the typical social profiles of the decision-makers, Hofstetter et al. (2000) and Miettinen and Hämäläinen (1997) have highlighted, by distinguishing between public and private decision-makers, that the initial LCA step itself, i.e., goal and scope, is also very subjective. Later, it has been shown 
that the methodological choices such as system boundaries (Tillman et al., 1994) or allocation method (Tillman, 2000) are linked to the goal and decision context of the LCA study, and a distinction was made between prospective and retrospective LCAs. This is now widely accepted by LCA actors. According to the International Reference Life Cycle Data System (ILCD) handbook (JRC, 2010) "the decision-context is one key criterion for determining the most appropriate methods for the Life Cycle Inventory (LCI) model, i.e., the LCI modelling framework (i.e., "attributional" or "consequential") and the related LCI method approaches (i.e., "allocation" or "substitution") to be applied".

Simultaneously, the concepts of foreground and background systems have been defined. They come from a literature review on the recycling and incineration with energy recovery of paper packaging materials conducted by Finnveden and Ekvall (1998), whose conclusion is that decision making is difficult because their results depend on a number of key issues related to political decisions from other domains, like heat and electricity production, waste management and forestry. Foreground and background concepts based on decision are defined by Frischknecht (1998). The foreground system is thus defined as the collection of "processes, which are under the control of the decision-maker for which an LCA is carried out" and the background system as the collection of "processes on which no or, at best, indirect influence may be exercised by the decision-maker for which an LCA is carried out". According to this, the elementary flows coming from foreground systems are generally quantified at a finer level of detail and accuracy than other processes with less detail and average value references.

The complexity of the LCA method, which requires in addition to multidimensional LCIA information, many subjective choices throughout the procedure, make decision making extremely difficult. Moreover, the number of subjective choices to be made within the LCA procedure is substantial and makes its results insecure: choices between compared scenarios, choices between equivalent input intermediary flows required from the background system, choices of system boundaries, choices of allocation methods, choices of impact assessment methods, etc. In general, several assumptions are made to reduce the number of choices to a few considered as important, which are generally tested using the oneat-a-time sensitivity analysis. However, reducing the combinations of choices to a small number, chosen by LCA experts, decreases transparency, enhances the subjectivity of the LCA results, and increases uncertainties at the same time. Furthermore, the one-at-atime sensitivity analysis neglects the possible interactions and generally assumes that the variations are linear.

The alternative approach proposed here is decidedly different. Returning to the fundamentals of decision, the decision-maker's role is assumed to consist in addressing problems with effective actions. Actions are considered to be effective only if they are controlled by the decision-maker and only if all possible alternatives and their implications are systematically and carefully compared. Rather than choosing between some environmental impacts that they barely understand, decision-makers are offered the possibility to choose between different effective actions within a controlled area of influence. Assuming that decision-makers do consider environmental impacts as a problem, we think that LCA experts must provide information about:

- the shared responsibility of the decision-maker in environmental impacts as an actor inside a whole system, i.e., distinguishing between impacts between foreground and background systems;

- the collection of actions that are possible and exhaustively and systematically controllable;
- the systematic comparison of the different environmental consequences of the various possible actions and their combinations.

This may be achieved by combining several sensitivity analysis methods (Morris screening method and Sobol global method) that do not require any predefined assumptions about the important choices, linearities or interactions. In order to meet the requirements of this approach, the concept of action-oriented LCA has been proposed (Senga Kiessé et al., 2013; Ventura et al., 2013). The objective of this research was to provide specific options for a decision-maker within a foreground system.

This method has been described in detail for the study of hemp production by crop producers (Andrianandraina et al., 2015). By using some models calculating the elementary flows in the foreground system and carrying out a sensitivity analysis, it has been possible to identify among all possible actions controlled by the farming actor, which parameters and technological options are best to enhance environmental performances. The efficiency of these options, called "action levers", is calculated according to the uncertainties introduced by the stochastic variations of uncontrolled parameters like climate variations or modelling choices, like allocation methods (Andrianandraina et al., 2015). Padey et al. (2014) have used the global sensitivity analysis to identify parameters including most of the uncertainties of prospective LCA results without conducting a local sensitivity analysis first. More recently, a protocol for global sensitivity analysis of impact assessment models in LCA has been studied in Cucurachi et al. (2016) by carrying out both local and global sensitivity analyses as in our present approach. Possibilities for actions, however, are not extracted from their protocol.

Our first study focused on the crop producer as the decision maker (Andrianandraina et al., 2015) and the economic actor in a cradle-to-gate system. However, in the next step of the life cycle, hemp can be transformed into an insulation product for buildings. To go further, it is necessary to introduce a new decision-maker as the economic actor of the industrial transformation of hemp.

The purpose of this article is to broaden our initial methodology by testing the introduction of the industrial producer as a second economic actor and as a new decision maker, in the product chain. By introducing this new actor, we aim at determining whether the actions of both actors are conflicting or not and which of the two actors has the most influence on which impact category. The industrial transformation phase of hemp straw into insulation material is examined as the foreground system. The same method (Andrianandraina et al., 2015) is used for this new actor, but the relationships between farming, industrial and construction actors is particularly examined to better understand possibilities and responsibilities for the improvement of environmental performances of each actor. Thus, compared to our previous study (Andrianandraina et al., 2015), this paper innovates by broadening the initial method by considering two successive actors (industrial and farming actors) simultaneously during a product's life cycle.

\section{General method and implementation through case study}

The identification of action levers relies on a combination of LCA and sensitivity analyses (SA). SA methods are used to assess the influence of model input parameters on output parameters (Sobol, 2001). Hamby (1994) proposes a review of some SA techniques with different objectives like the study of the influence of model parameters, the calibration or simplification of models, or the identification of important research subjects. A local SA can be conducted to determine the consequences on the model response of a small change in one input parameter at a time; while, a global 
SA can be conducted to measure how much each input parameter contributes to the output variance by using a method to perform uncertainty propagation, if the probability distribution function of the input parameter is known.

Several methods for global SA have been applied in LCA literature such as Spearman correlation coefficient (Chen and Corson, 2014), Sobol method (Padey et al., 2014) or regression coefficients (Basset-Mens et al., 2009). The present approach combines Morris' (1991) local qualitative method with Sobol's (2001) global quantitative method (details of both methods will be presented in Section 2 in Supplementary Material). These two methods are selected on the basis of the available data and models in our study: indeed, Morris' method just requires to know the variation range of input parameters, while Sobol's method does not require linear modelling assumptions. Furthermore, these two methods are complementary. First, the Sobol method is time-consuming whereas the Morris method is fast, and allows to determine non-influential parameters. Second, the Morris method provides more information than the Sobol method regarding parameter trends. The Sobol method, on the other hand, provides some quantitative information on the global influences of parameters taken individually, or grouped, and in interaction with each another. Both methods contribute toward providing decision-makers with complementary information.

The coupling procedure between SA and life cycle thinking is presented in Fig. 1. It involves the following five steps. In step I (Fig. 1), the goal and scope of the study are defined as in a classic LCA process. However, the system of the product life cycle is analysed in terms of interactions between the economic actors, which generates separate sub-systems, each corresponding to the foreground system of a given actor. Each sub-system has its particular functional unit, through which it is connected to the next subsystem (Fig. 2). In step II (Fig. 1), the elementary processes for the chosen foreground system of the actor considered are identified, as well as the models providing inventory data. In step III (Fig. 1), all the input variables used for inventory models are characterized by their distribution probabilities and grouped into different categories according to the possible actions by the actor (Ventura et al., 2013): (i) variables with a direct control are defined as technological (corresponding to the possible action levers); (ii) variables with a possible indirect control or no control at all (constraints) are defined as contextual; and (iii) modelling variables that are not controlled by the economic actor but by the LCA modelling expert, are defined as methodological. In step IV (Fig. 1), the local and global sensitivity analyses are successively carried out. First (IVa in Fig. 1), the Morris method is applied as a screening SA to rank influential parameters, identify their variation trends and reduce the number of parameters considered in the next step, is conducted. Second, the Sobol method (IVb in Fig. 1) is applied as a global SA to quantify the influence of each influential parameter on the considered impact category and the interactions between the influential parameters. Finally, step V (Fig. 1) consists in interpreting the results through the implementation of the scenarios corresponding to strong or weak impacts. During this step, the (technological) action levers are identified and potential eco-design scenarios are proposed for each economic actor.

Each step is described in more detail in the following subsection where the general methodological principles and steps I to IV are presented in the context of the case study (Fig. 1). Step V will be detailed in Part 3 of this article (Results).

\subsection{Step I: definition of the case study system}

\subsubsection{General description of the case study}

Hemp produces hemp stems, also called hemp straw, which is the output result for the farming sub-system. The initial industrial

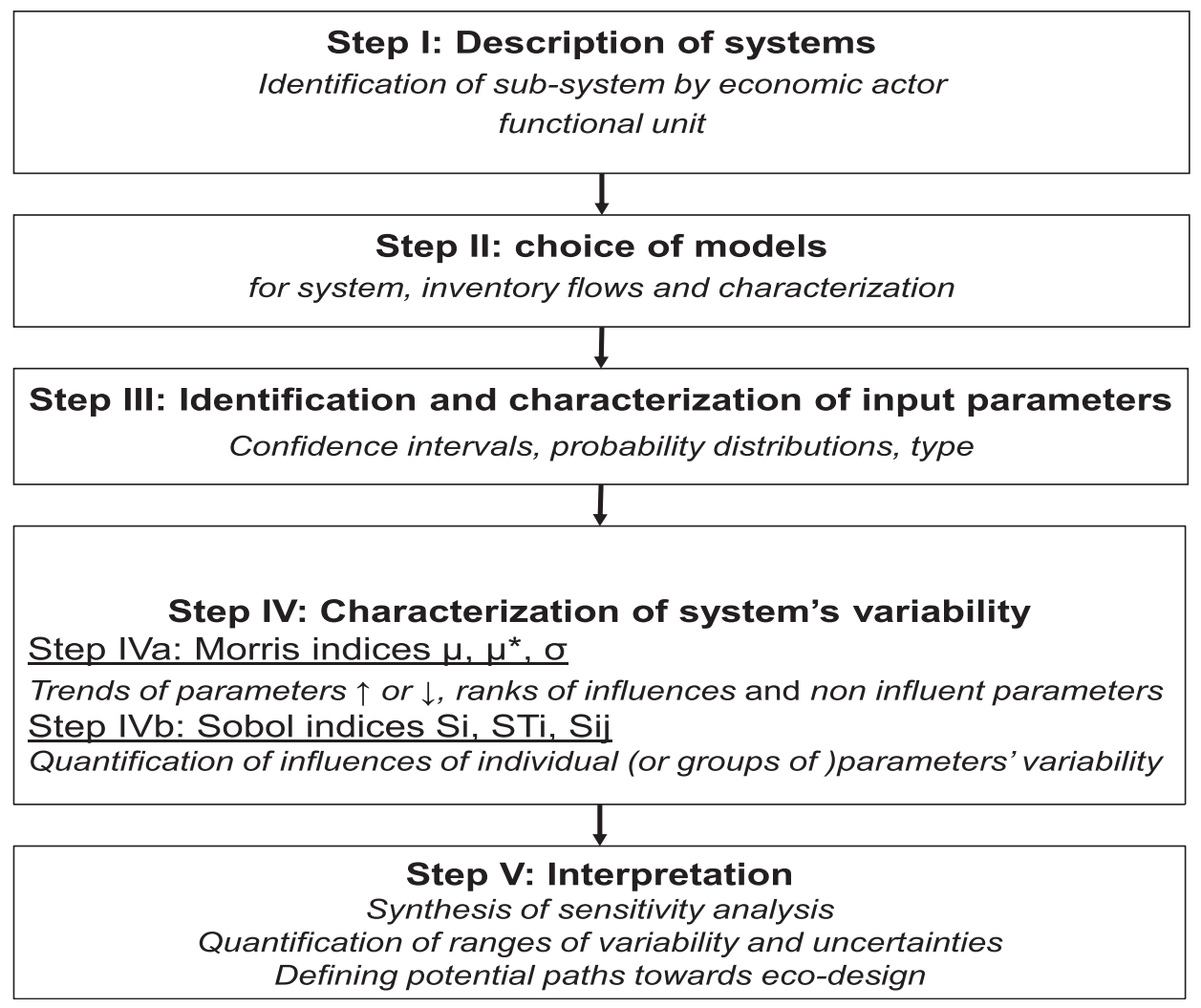

Fig. 1. Steps involved in the combined LCA-SA method. 


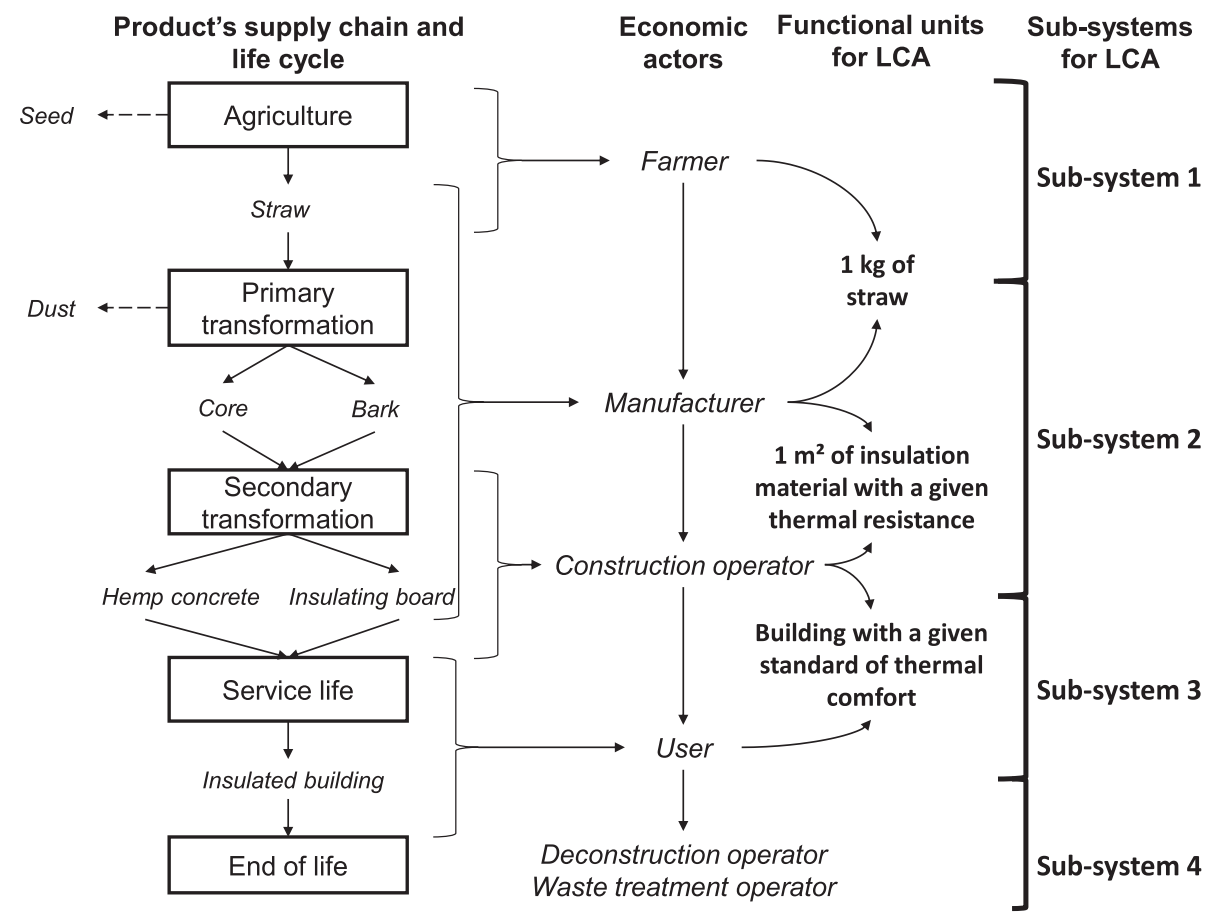

Fig. 2. Selection of sub-systems and functional units according to economic actors.

transformation step generates two main raw materials used in various domains like civil engineering: the woody core or core (approximately 55\% in mass) and the bark (approximately 30\% in mass), which contains long bast fibres (Van der Werf et al., 1994). Hemp dust (approximately 15\%) is also produced, but not always considered as a product by LCA because it is not always valued. Both hemp bast fibres and hemp core can be used, among other things, in the manufacturing of building materials because of their insulating properties. The so-called hemp concrete, (a mixture of hemp core, lime and water) is a multifunctional material used in construction because of its interesting mechanical, thermal and acoustic properties (Tran Le et al., 2010). Hemp-based products are increasingly used by building actors, because hemp is a considered as a renewable resource and a potential carbon sink.

In the case study, the studied foreground system is the hemp industrial transformation system (Sub-system 2 in Fig. 2), the hemp crop production system is part of the background system (Subsystem 1 in Fig. 2), which is thus a cradle-to-gate system. The industrial actor receives the input material (hemp straw) from the agricultural actors and simultaneously produces two insulation products for building actors. The agricultural sub-system (Andrianandraina et al., 2015) is not described here but is detailed in the Supplementary Material. The industrial transformation sub-system detailed in Fig. 3 presents the background and foreground system processes.

\subsubsection{Functional units}

The functional unit is chosen to represent the use for which the product has a value on the market. In the present case, according to construction actors, the main function of hemp-based products is thermal insulation. Functional units have thus been chosen, to provide one square meter $\left(\mathrm{m}^{2}\right)$ of insulation board with a thermal resistance of $2.44 K . \mathrm{m}^{2} \mathrm{w}^{-1}$ for a typical duration of 50 years and one square meter $\left(\mathrm{m}^{2}\right)$ of wall with a thermal resistance of $2.36 \mathrm{~K} . \mathrm{m}^{2} \mathrm{w}^{-1}$ for a typical duration of 100 years, respectively. The functional units of both products are not equivalent, since it is not the goal to compare both insulation products. In particular, the two products have different typical durations based on the definition of their functional unit from Inies database (more details are given in Subsection 5.1 in Supplementary Material). The thermal resistance is assumed constant for both products.

\subsection{Step II: models for the systems}

The modelling of the inventory of the industrial production subsystem is described (Fig. 3). The global model includes different types of sub-models that are detailed in this part. Some physicochemical models are used for calculating the inventory flows in the foreground sub-system. Others are decision models that are represented by logical tests (Fig. 4) for the choice of an electricity mix or an allocation method.

\subsubsection{Hemp transformation process models}

The industrial transformation of hemp straw is carried out in two steps. The initial transformation process consists in a mechanical operation realized on dry hemp stems to separate the bark from the rest of the stem (previously, water retting was used). Energy and emissions for the initial transformation step depend on the equipment. Different scenarios are available, corresponding to different choices of energy sources: electricity, diesel fuel and propane gas (more details are given in Section 3 and in Tables S5-S6 in Supplementary Material). The equipment scenarios are taken into account because they are useful for defining the variation range of the different energy consumptions.

Secondary transformation processes concern bark and core (Inies database, Tran Le et al., 2010). Bark is mixed with polyester resin to manufacture insulation boards, whereas core in granular form is used in combination with binder products (lime and water) to obtained hemp concrete (more details are given in Section 4 and in Table S7 in Supplementary Material).

Considering the total electricity production, the industrial actor is assumed to produce locally a fraction of photovoltaic electricity, $\alpha$ $\%$, which is completed with a fraction $(1-\alpha) \%$ of national mix electricity (Fig. 3). The photovoltaic electricity produced locally 


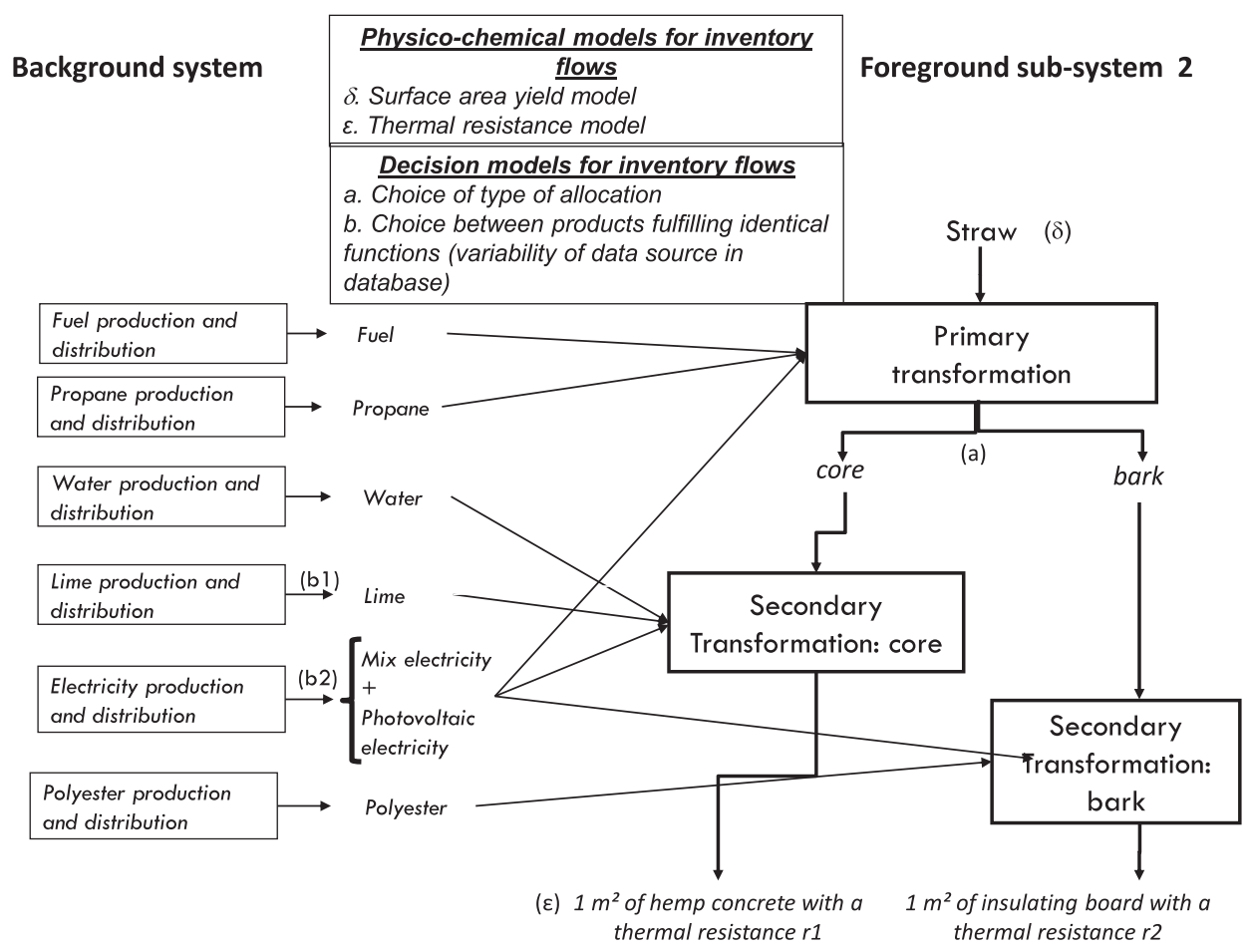

Fig. 3. LCI modelling for industrial transformation (sub-system 2).

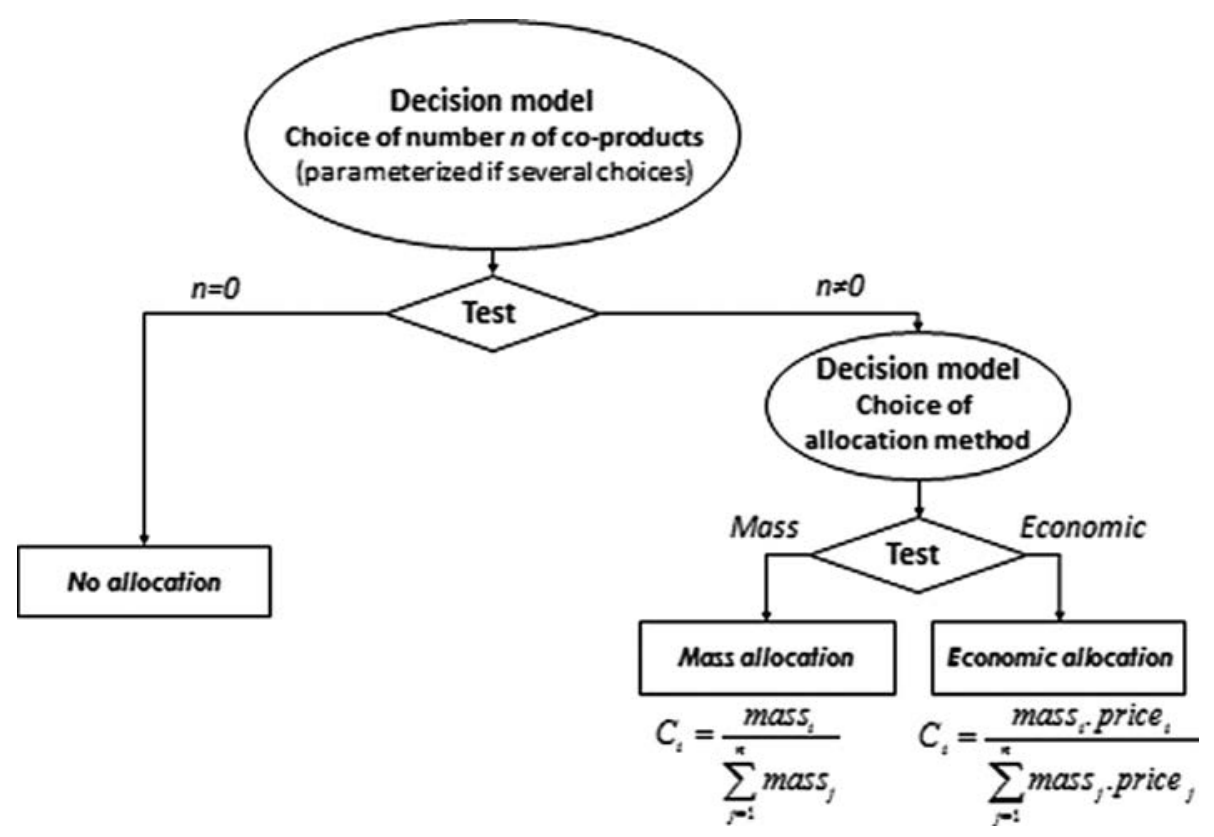

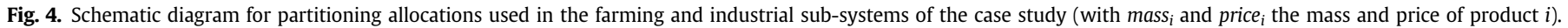

depends both on the average annual yield of the photovoltaic process and the surface area of photovoltaic panels (more details are given in Section 3 in Supplementary Material). A maximum area of $1500 \mathrm{~m}^{2}$ of photovoltaic panels with a yearly energy output of $1350 \mathrm{kWh} / \mathrm{kWp}$ is considered (Photovoltaic Geographical Information System, PVGIS, http://re.jrc.ec.europa.eu/pvgis/). This high solar photovoltaic production for France has been chosen to maximize the amount of electricity generated. However, in spite of this assumption, the photovoltaic electricity produced locally only represents $\alpha=1.25 \%$ of the total electricity annually needed for the process of 5000 tons of hemp straw (more details are given in Subsection 3.1 in Supplementary Material).

Calculated LCA inventories are detailed in the Supplementary Material part (Sections 3 and 4).

Some life cycle inventory data from the ecoinvent database (version 2.2) have been used for the background processes. The Center of Environmental Science of Leiden University (CML) 2001 and Cumulative Energy Demand (CED) characterization methods are applied. The following impacts are considered: climate change (100-year global warming potential), acidification (average 
European acidification potential), eutrophication (generic eutrophication potential), human toxicity (100-year human toxicity potential). Furthermore, the ecotoxicity impact (100-year ecotoxicity) is considered to be the sum of the freshwater aquatic ecotoxicity (100-year freshwater aquatic ecotoxicity potential), marine aquatic ecotoxicity (100-year marine aquatic ecotoxicity potential), terrestrial ecotoxicity (100-year terrestrial ecotoxicity potential), marine sediment ecotoxicity (100-year marine sediment ecotoxicity potential) and freshwater sediment ecotox (100-year freshwater sediment ecotoxicity potential) impact categories. The land competition impact is also considered.

\subsubsection{Allocation models}

The decision models used to select the number of co-products or the type of allocation partitioning used within the farming and industrial sub-systems are shown schematically in Fig. 4. In the present study, only partitioning allocation alone is considered. Partitioning allocations are generally based on mass or economic values. Allocation can also be based on the energy content, however, this is mainly used when the energy content is an important product characteristic (for fuels and food products, for instance), which is not the case here. We consider that one type of allocation, either mass or economic, is used for all sub-systems. Consequently, a generic qualitative parameter, called Allocation method, is introduced to code the allocation method with a value of 1 for mass allocation and 2 for economic allocation.

For the farming system the production and harvesting of $1 \mathrm{~kg}$ of hemp straw have been previously modelled (Andrianandraina et al., 2015). Hemp crops can produce either straw, or both straw and seed. The choice between these types is made by the farming actor and depends on the demand for hemp seed. A qualitative parameter, called the Crop production scenario, is introduced to code the crop production scenarios: a value of 1 for the production of straw only, 2 for the production of straw and seed. This parameter is defined as a contextual parameter, because it is chosen by the farming actor. At this level, allocation takes place only if both straw and seed are produced (Crop production scenario $=2$ ). For the transformation processes, based on the fact that hemp dust may be further valued or not, a qualitative parameter called Hypothesis on hemp co-products is introduced. This parameter shows how allocation coefficients are calculated: a value of 1 is given when two coproducts (bark and core) are considered and a value of 2 when three co-products (bark, core and dust) are considered. Allocation coefficients involve mass ratios and prices per unit of products, which are considered as contextual parameters.

\subsection{Step III: characterization of the input parameters}

In the present case study, the industrial actor is the central actor. Nevertheless, all the farming sub-system parameters, which have been considered as influential in a previous study (Andrianandraina et al., 2015) have been kept as parameters in the SA of the industrial transformation sub-system (Table 1). The detailed parameters are presented in Tables S1 and S2 of Section 1 in the Supplementary Material Part.

To characterize the input parameters, the detailed description parameters are presented in the Supplementary Material Part, Sections 1, 3 and 4. All relevant information on reference (default or recommended) values, types (among the three groups of parameters obtained from the previously defined classification), variation range, and probability density functions (pdfs) have been collected from the literature or obtained from expert judgments. The pdf is assigned as follows: a uniform discrete distribution is set for all the qualitative or quantitative integer value parameters; a uniform continuous distribution is set for the parameters with a known variation range; a triangular distribution is set for the parameters with existing recommended values and a known variation range; and finally, a normal distribution is set for the parameters described by their mean value and standard deviation.

\subsection{Step IV: characterization of the system variability: sensitivity analysis study}

For the Morris indices, the input parameters $X_{i}$ are discretized in 10 values and the prescribed number of trajectories is $r=30$ (with a number of elementary effects computed for each parameter). For the Sobol indices, 500 bootstrap replications 5000 in size from a sample initial size $N=10,000$ are run. A Sobol index confidence interval is then estimated by considering the $5 \%$ and $95 \%$ percentiles. For each insulation product studied separately, Morris and Sobol's methods are successively applied at the level of the impact indicators. The results presented below refer to the study per parameter.

The basic interpretation for each statistical analysis consists of

Table 1

Influent parameters from the crop production subsystem and parameters from the industrial transformation sub-system separated into three categories.

\begin{tabular}{|c|c|c|}
\hline Technological & Contextual & Methodological \\
\hline \multicolumn{3}{|l|}{ Hemp crop production } \\
\hline 1. Crop production scenario & 1. Clay content of the soil & 1. Allocation method \\
\hline 2. Engine rated power & 2. Seeds yield & 2. $\mathrm{N}_{2} \mathrm{O}$ direct field emission factor \\
\hline 3. Engine release year & 3. Seed price & \\
\hline 4. Motor rating & 4. Soil type & \\
\hline 5. Quantity of N fertilizer applied & 5. Straw yield & \\
\hline 6. Type of mineral fertilizer & 6. Straw price & \\
\hline \multicolumn{3}{|l|}{ 7. Working speed } \\
\hline \multicolumn{3}{|l|}{ Industrial transformation } \\
\hline 8. Photovoltaic annual yield & 7. Mass of hemp bark per ton of straw & 3. Hypothesis on hemp co-products: including or not hemp dust as co-product \\
\hline 9. Photovoltaic surface board & 8. Mass of hemp core per ton of straw & \\
\hline 10. Quantity of propane per ton of straw & 9. Price of hemp bark & \\
\hline 11. Quantity of electricity per ton of straw & 10. Price of hemp core & \\
\hline \multicolumn{3}{|l|}{ 12. Quantity of diesel per ton of straw } \\
\hline \multicolumn{3}{|l|}{ 13. Quantity of hemp core } \\
\hline \multicolumn{3}{|l|}{ 14. Quantity of hydraulic lime } \\
\hline \multicolumn{3}{|l|}{ 15. Quantity of water } \\
\hline \multicolumn{3}{|l|}{ 16. Quantity of electricity for hemp core } \\
\hline \multicolumn{3}{|l|}{ 17. Quantity of hemp bark } \\
\hline \multicolumn{3}{|l|}{ 18. Quantity of polyester } \\
\hline 19. Quantity of electricity for hemp bark & & \\
\hline
\end{tabular}


investigating the following parameters.

For the Morris method, three parameters (averages $\mu_{i}$ and $\mu_{i}^{*}$, standard deviation $\sigma_{i}$ ) are calculated so that:

- the higher $\mu_{i}^{*}$, the more influential the parameter;

- high standard deviation values $\sigma_{i}\left(\sigma_{i} / \mu_{i}^{*} \geq 0.5\right)$ reveal the nonmonotonic behaviour or some possible interactions between parameters;

- for $0.1<\sigma_{i} / \mu_{i}^{*}<0.5$, the effect of the parameter is considered monotonic and for $\sigma_{i} / \mu_{i}^{*}<0.1$, it is considered linear (Garcia Sanchez et al., 2013);

- the algebraic sign of $\mu_{i}$ indicates an increasing (i.e. positive sign) or decreasing (negative sign) trend of the indicator in relation to the considered parameter.

Tables S5 and S6 (Supplementary Material) display the standard deviation values $\sigma_{i}$ and, the averages $\mu_{i}$ and $\mu_{i}^{*}$.

For the Sobol method, only the first $\left(S_{i}\right)$ and total $\left(S T_{i}\right)$ order index values are examined for each parameter with its tendency (depending on the algebraic sign of $\mu_{i}$ ) for each parameter found to have the most important influence on the production processes of insulation boards and hemp concrete (Fig. 2). The first order index quantifies the main effect of a parameter the on model outputs. The total order index quantifies the total effect of a parameter, including its interaction with other parameters. Both indices are defined as:

- the higher $S_{i}$, the more influential the parameter;

- the $S T_{i}-S_{i}$ difference close to zero indicates that the interaction between $X_{i}$ and the other parameters is negligible.

In general, only the parameters with $S_{i}>0.10$ are presented, however some parameters with $S_{i}<0.10$ may also be presented when ranking among the most influential parameters.

\subsection{Step V: interpretation of results}

\subsubsection{Identification of action levers}

With the aim of providing suitable information to decisionmakers, it is first necessary to analyse whether a single parameter influences LCIA indicators differently. Indeed, if one parameter has a large opposite influence depending on the LCIA indicators, its relevancy as an action lever for improving environmental performances is disputable. Other parameters should then be preferred. Second, it is also necessary to analyse whether a single parameter has an opposite influence depending on the economic actor for the same LCIA indicator. In this case, the favourable effects observed by the action of one actor can be adversely counterbalanced by the action of another actor for the same parameter, reducing thus the overall effect. Consequently, the estimation of the optimal value of the parameter between the different actors ensures the best environmental performance.

\subsubsection{Significance of the action levers' influence}

Once all the key technological parameters are identified, LCA results to assess the consequences of the actors' possible decisions can be calculated. Environmental impacts are compared either with a favourable set of parameters or with an average set of default parameters, using the Monte Carlo (MC) simulations (considering a sample size of 5000). The MC sampling method is used here because it allows for integrating probabilistic distribution function (pdf) when generating values, although it requires a large number of repetitions because of a slower convergence speed.

The set of favourable parameters is calculated by setting all the influential technological parameters from the industrial sub-system at their most favourable values (with the influential contextual and methodological set of parameters identical to the default scenario, i.e., according to their pdf). All the non-influential technological parameters are set at their default or recommended value.

The set of default parameters is calculated by setting all the influential technological parameters from the industrial sub-system at their default value and all the influential contextual and methodological parameters according to their pdf (Tables S3, S6-S7 in Supplementary Material).

All parameters from the background system are set according to their pdf (Table S2) in both options when focusing on the technological action levers of an isolated actor (here the industrial actor).

\section{Results}

In this section, results for each product as well as for the industrial production foreground system with joint production are presented. The full results of Morris and Sobol SA are given in Section 6 of Supplementary Material (Tables S8-S13).

\subsection{Identification of action levers}

For both products, some general remarks can be made regarding both Morris and Sobol SA results for all impact categories and for both insulation products.

For almost all the parameters, the ratio $\sigma_{i} / \mu_{i}^{*}$ ranges within the interval $[0.1 ; 0.5]$ showing some possible interactions and/or a nonlinearity of the parameter effects.

The two following sub-sections present the SA results for each industrial product separately. The analysis of the results focuses on the most influential parameters per impact category while considering the significant interactions $\left(S T_{i}-S_{i} \geq 0.1\right)$ between them as well.

\subsubsection{Insulation board product}

Results in Table 2 show that all environmental impacts are generated during the hemp crop production phase, except climate change and Cumulative Energy Demand (CED).

For climate change, the quantity of polyester consumed for the transformation of hemp bark is the most influential lever (50\%) with an increasing trend. The production of synthetic fibres, indeed, emits high amounts of carbon dioxide; e.g., $1.85 \mathrm{~kg}$ of $\mathrm{CO}_{2}$ is emitted per kilogram of poplypropylene produced (Boutin et al., 2006). Furthermore, this parameter is also influent with interactions (12\%). The crop production scenario and the straw yield, controlled by the farming actor are both influential (12\%) at the industrial production level.

For $C E D$, two technological parameters from the industrial subsystem appear entirely responsible for the variation in this impact category: the quantity of electricity consumed for hemp bark transformation (95\%) and the quantity of polyester (9\%).

For all the other indicators, the parameters from the farming system are the most influential. Their influence has already been shown and discussed in Andrianandraina et al. (2015).

It can also be noticed that, even although the allocation method does not appear as an influential parameter, it has a non-negligible interaction effect with the crop production scenario (23\%) and the type of mineral fertilizer ( $8 \%$ ).

\subsubsection{Hemp concrete product}

Similar to insulation board production, the influence of the parameters from the industrial sub-system on impacts is particularly significant for climate change and CED for the hemp concrete product. More specifically (Table 3), the quantity of hydraulic lime can be considered as a first ranking influential parameter for climate change (76\%) and for CED (35\%). The production process of 
Table 2

Results of the sensitivity analysis for the most influential parameters on impact categories in relation to the production of insulation boards.

\begin{tabular}{|c|c|c|c|c|}
\hline Impact categories & Parameters & Algebraic sign of $\mu_{i}$ & Sobol first indices $S_{i}$ & Sobol total index $S T_{i}$ \\
\hline \multirow[t]{3}{*}{ Climate change } & Quantity of polyester ${ }^{\mathrm{a}}$ & + & $50 \%$ & $62 \%$ \\
\hline & Crop production scenario & - & $12 \%$ & $22 \%$ \\
\hline & Straw yield & - & $12 \%$ & $14 \%$ \\
\hline \multirow[t]{3}{*}{ Acidification } & Type of mineral fertilizer & + & $41 \%$ & $50 \%$ \\
\hline & Crop production scenario & - & $13 \%$ & $31 \%$ \\
\hline & Straw yield & - & $7 \%$ & $10 \%$ \\
\hline \multirow[t]{3}{*}{ Eutrophication } & Clay content of the soil & - & $20 \%$ & $48 \%$ \\
\hline & Crop production scenario & - & $9 \%$ & $23 \%$ \\
\hline & Group of non-influential parameters from agricultural system & no sign & $9 \%$ & $32 \%$ \\
\hline \multirow[t]{3}{*}{ Human toxicity } & Engine release year & - & $40 \%$ & $52 \%$ \\
\hline & Working speed & - & $10 \%$ & $18 \%$ \\
\hline & Engine rated power & + & $10 \%$ & $14 \%$ \\
\hline \multirow[t]{4}{*}{ Ecotoxicity } & Engine release year & - & $24 \%$ & $31 \%$ \\
\hline & Quantity of electricity consumed for hemp bark (Transf. 2) & + & $11 \%$ & $11 \%$ \\
\hline & Working speed & - & $10 \%$ & $18 \%$ \\
\hline & Rating motor & + & $6 \%$ & $9 \%$ \\
\hline \multirow[t]{2}{*}{ Cumulative energy demand } & Quantity of electricity consumed for hemp bark (Transf. 2) ${ }^{\mathrm{a}}$ & + & $95 \%$ & $96 \%$ \\
\hline & Quantity of polyester ${ }^{\mathrm{a}}$ & + & $9 \%$ & $9 \%$ \\
\hline \multirow[t]{3}{*}{ Land competition } & Crop production scenario & - & $31 \%$ & $65 \%$ \\
\hline & Straw yield & - & $18 \%$ & $22 \%$ \\
\hline & Hypothesis on hemp co-products & - & $5 \%$ & $7 \%$ \\
\hline
\end{tabular}

a Technological parameters from the industrial sub-system.

Table 3

Results of the sensitivity analysis for the most influential parameters on impact categories in relation to the production of hemp concrete.

\begin{tabular}{|c|c|c|c|c|}
\hline Impact categories & Parameters & Algebraic sign of $\mu_{i}$ & Sobol first indices $S_{i}$ & Sobol total index $S T_{i}$ \\
\hline \multirow[t]{3}{*}{ Climate change } & Quantity of hydraulic lime ${ }^{a}$ & + & $76 \%$ & $77 \%$ \\
\hline & Allocation method & - & $11 \%$ & $25 \%$ \\
\hline & Straw yield & - & $10 \%$ & $10 \%$ \\
\hline \multirow[t]{3}{*}{ Acidification } & Type of mineral fertilizer & + & $30 \%$ & $36 \%$ \\
\hline & Allocation method & - & $19 \%$ & $30 \%$ \\
\hline & Straw yield & - & $6 \%$ & $9 \%$ \\
\hline \multirow{3}{*}{ Eutrophication } & Allocation method & - & $16 \%$ & $24 \%$ \\
\hline & Clay content of the soil & - & $15 \%$ & $40 \%$ \\
\hline & Group of non-influential parameters from agricultural system & no sign & $9 \%$ & $27 \%$ \\
\hline \multirow[t]{4}{*}{ Human toxicity } & Engine release year & - & $35 \%$ & $48 \%$ \\
\hline & Engine rated power & + & $9 \%$ & $18 \%$ \\
\hline & Working speed & - & $9 \%$ & $13 \%$ \\
\hline & Allocation method & - & $7 \%$ & $15 \%$ \\
\hline \multirow[t]{4}{*}{ Ecotoxicity } & Engine release year & - & $28 \%$ & $39 \%$ \\
\hline & Allocation method & - & $10 \%$ & $21 \%$ \\
\hline & Working speed & - & $8 \%$ & $16 \%$ \\
\hline & Engine rated power & + & $7 \%$ & $10 \%$ \\
\hline \multirow[t]{3}{*}{ Cumulative energy demand } & Quantity of hydraulic lime & + & $35 \%$ & $35 \%$ \\
\hline & Allocation method & - & $23 \%$ & $47 \%$ \\
\hline & Quantity of hemp core & + & $10 \%$ & $15 \%$ \\
\hline \multirow[t]{3}{*}{ Land competition } & Allocation method & - & $36 \%$ & $55 \%$ \\
\hline & Straw yield & - & $13 \%$ & $16 \%$ \\
\hline & Crop production scenario & - & $12 \%$ & $26 \%$ \\
\hline
\end{tabular}

a Technological parameters from the industrial sub-system.

hydraulic lime requires high amounts of non-renewable energy because limestone must be heated over $900{ }^{\circ} \mathrm{C}$ (Boutin et al., 2006) while carbon dioxide is emitted by the consumption of fossil energy and by the chemical reactions of carbonates. The influential parameters from the industrial actor have almost no interactions.

For acidification, eutrophication, human toxicity, ecotoxicity and land competition, the parameters with the greatest influence are the same than for the insulation boards: they result from the farming sub-system and have been exhaustively analysed previously (Andrianandraina et al., 2015).

The main difference with the insulation board product comes from the allocation method, which appears to have a significant influence. The choice between mass and economic allocation for the production of hemp concrete has a major influence for land competition (37\%) and eutrophication (16\%), and is the second most influential parameter for all the other impact categories. However, these interactions appear with the parameters from the farming sub-system only. As regards hemp concrete, the impacts are more evenly distributed between the co-products (bark, core and, when relevant, dust) when using the economic allocation than the mass allocation (Table 3 ). The economic allocation thus appears to be the most favourable for hemp concrete. It is, however, not unfavourable to the insulation board, because it is counterbalanced by the predominance of a favourable influence from the economic allocation as pointed out for hemp straw in farming sub-system (Andrianandraina et al., 2015). The qualitative parameter hypothesis on hemp co-products (with the inclusion or not of hemp dust as co-product) was expected to be favourable because including a third co-product logically reduced the impacts of the other coproducts with partition allocation. The results confirm this favourable influence $\left(\mu_{i}<0\right)$, which, however, does not appear prominently. The predominant influence of the allocation method 
for hemp concrete products hinders the individual influence of the other parameters in comparison with insulation board ones.

\subsection{Significance of the action levers' influence}

In this section, the focus is placed on the industrial sub-system technological parameters for reducing environmental impacts when considering that the industrial actors cannot control the technological parameters from the farming sub-system.

A regards insulation boards, only the results for climate change and CED are shown in Fig. 5 (full results are presented in Supplementary Material, Sub-section 6.3, Fig. S2 and Table S14). The impacts for the favourable scenario, in relation to the default scenario, are reduced by $20 \%$ or $13 \%$, depending on the impact category. For the CED impact category, a reduction of $13 \%$ of the impacts with a small variability of the pdfs (Fig. 5 (b)). For the other impact categories, however, an overlap of the pdfs from the default or favourable set of parameters is observed and the industrial actor variability reduction is consequently not significant.

Moreover, if all the influential technological parameters from both farming and industrial actors are set at their most adequate values, some reductions of $88 \%-6 \%$ are observed, depending on the impact category, in comparison with the case where only the action possibilities of the industrial actor are investigated (see Table S16 in
Supplementary Material). The cumulative action of the two actors is highlighted for impact categories where technological parameters have significant impact, like human toxicity or ecotoxicity, for instance (see Table $\mathrm{S} 1$ for the influential parameters in farming subsystems).

Concerning the hemp concrete product, the results for climate change and land competition are presented in Fig. 6 (full results are found in Supplementary Material, Sub-section 6.3, Fig. S3 and Table S15). For all the impact categories, some reductions of $20 \%-$ $18 \%$ are observed for the favourable scenario for the action levers available for the industrial actors, in comparison with the default scenario. The pdfs for both scenarios, however, overlap. The smallest overlaps are observed for climate change (Fig. 6 (a)) and CED (Fig. 6 (b)), for which the variability of the pdfs is lower than for the other impact categories. As regards land competition (Fig. 6 (b)), the pdfs have two distinct peaks corresponding to the two allocation methods ranked as first influential parameters. This result contrasts with the insulation board case, for which the selection of the allocation method has less influence and the pdf is unimodal on all the impact categories.

In the case of the combination of the favourable technological scenario for farming sub-systems with the favourable technological scenario for the industrial sub-systems, reductions of $92 \%-4 \%$ are observed compared with the scenario where only the favourable

(a)
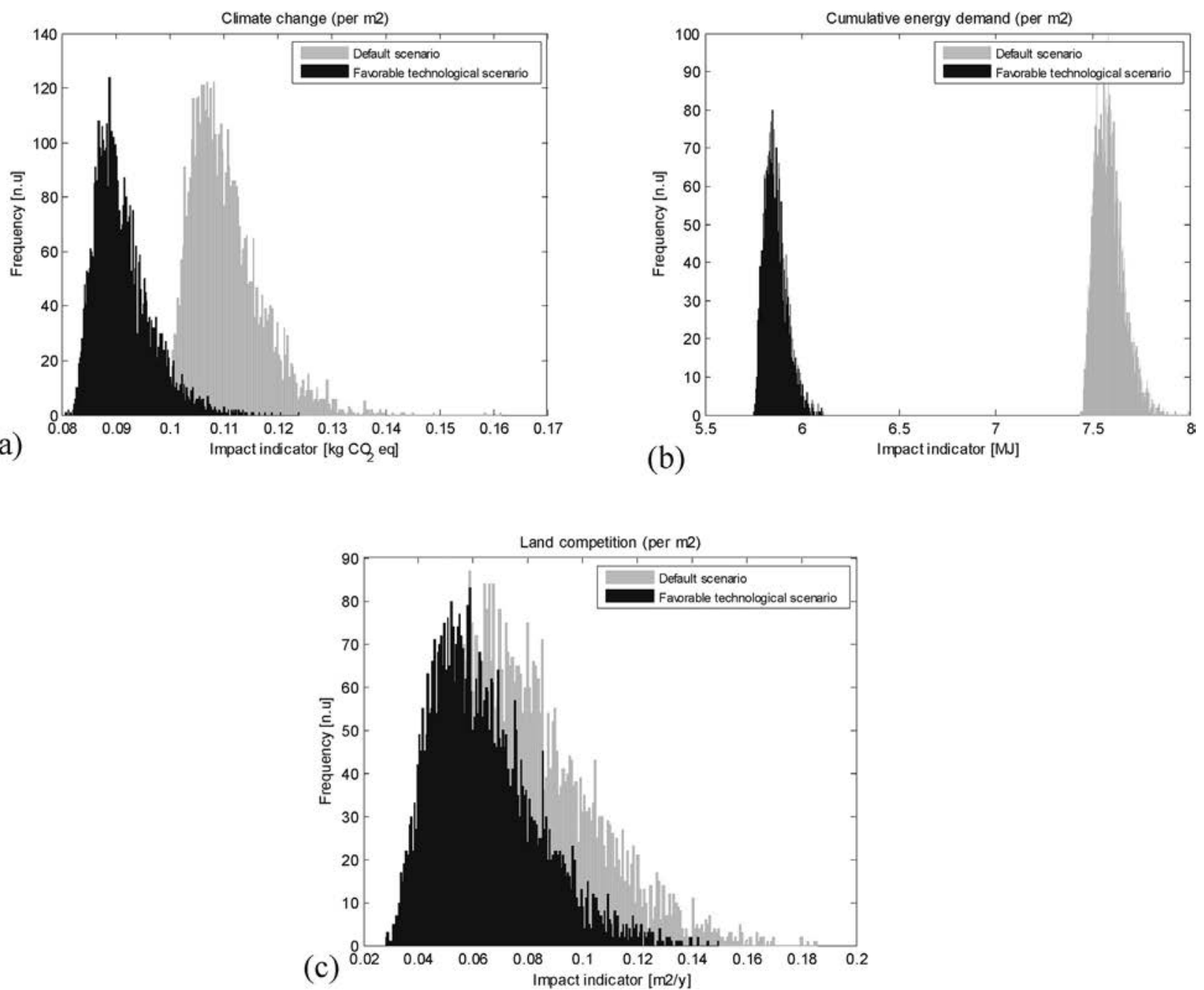

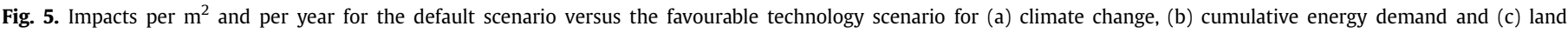
competition for insulation board product. 

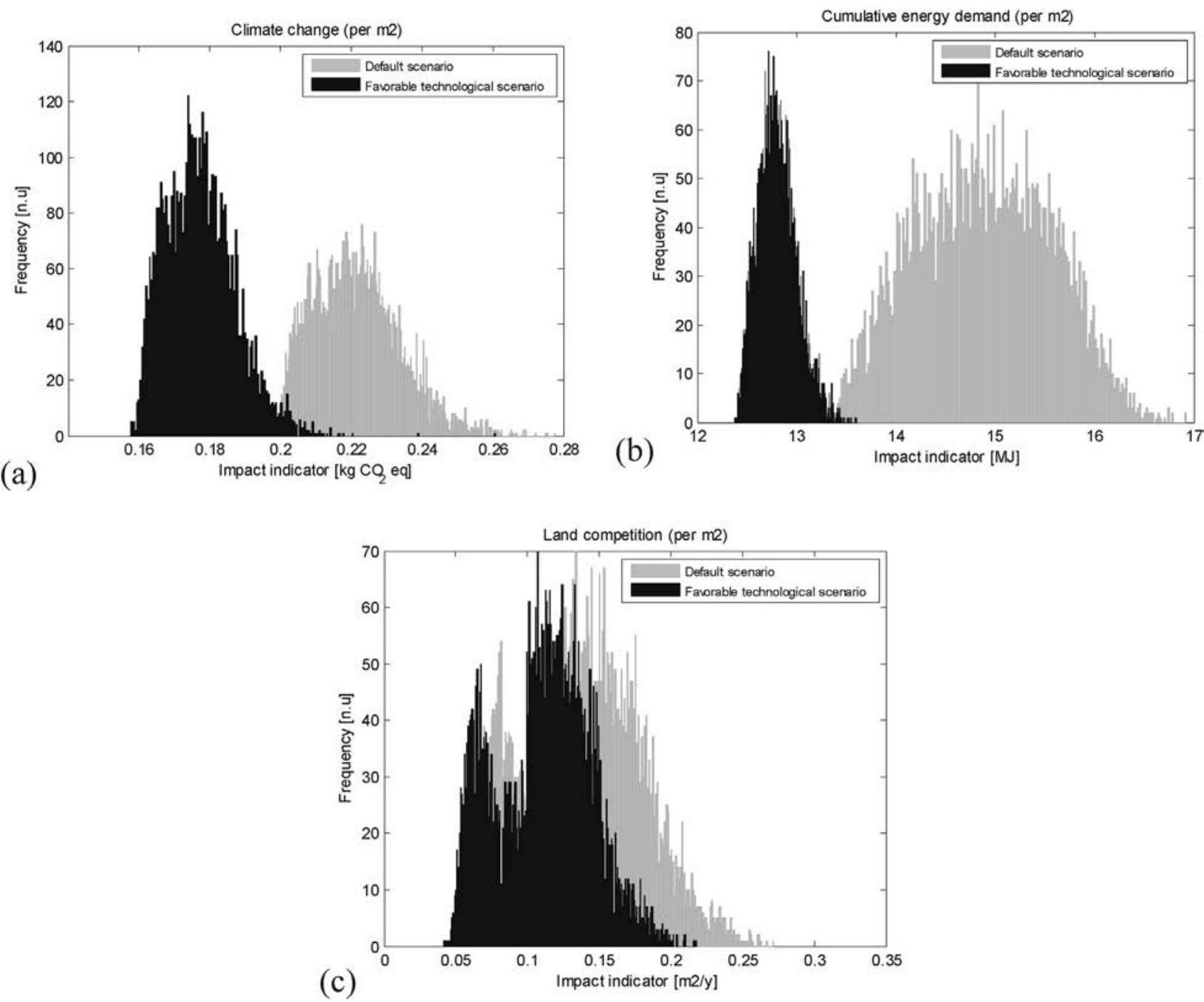

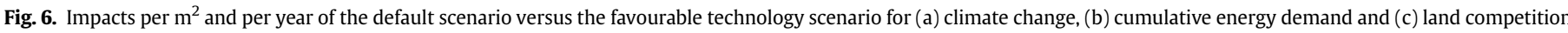
for hemp concrete product.

actions of the industrial actor are considered. The joint action of two actors allows for the most important reductions for the same impact categories than for the insulation boards (Table S17 in Supplementary Material).

\section{Discussion}

\subsection{Possible scenarios for eco-design}

First, a set of technological recommendations which are potential scenarios towards an eco-design approach for industrial actors based on identified technological action levers is presented.

For the industrial actor, whatever the product considered, reducing quantities of hydraulic lime (in agreement with the findings by Boutin et al. (2006) for hemp concrete), quantities of polyester and quantity of consumed electricity during the secondary transformation are possible action levers to reduce the impacts on climate change and cumulative energy demand. However, the reduction in binder (hydraulic lime or polyester) quantity will reduce the thermal resistance of both insulation products. An antagonistic effect may then occur when integrating the use phase in the life cycle system because the reduction of the thermal resistance is susceptible to increase energy consumption.
Furthermore, the structural properties and durability are also important factors. A survey of the literature reveals that lime proportion in hemp concrete can vary from $25 \%$ to $55 \%$ (Collet et al., 2013) depending on the use intended (walls (Evrard and Herde, 2010), roofs, or floors) and the expected rigidity and lightness (Cérézo, 2005). More work needs to be carried out to understand this action lever better, which will be investigated in future studies. A total assessment including the use phase would enhance the definition of the limits for which this reduction can be acceptable with a view to construction and users as actors of the next steps of the life cycle. It would also be interesting to investigate the hydraulic lime or polyester production processes and explore the conditions for better performances. Other options are also available, such as the use of some alternative binder materials like starch (Tran Le, 2010) or cellulose. However further investigations are necessary to establish whether these new materials can significantly reduce the climate change impact.

Replacing the average French grid power system by local production of electricity using photovoltaic panels will have no influence on the environmental performances of the industrial site or on the LCAs of the products, because the surface area available for the panels is too small. $\alpha=15 \%$ for local power generation would require a surface area of approximately $18,000 \mathrm{~m}^{2}$ of photovoltaic 
panels. This action would probably be more effective at the national energy policy level. To verify the validity of this assumption, we examine the relevance of the $15 \%$ share of photovoltaic electricity in the total electricity consumption per year. This value corresponds to a 30-year projection of the French energy transition policy. According to this scenario, the use of photovoltaic electricity has a positive influence by reducing CED by $31 \%$ for the insulation board production. The results highlight a non-linear relationship between the input parameters of the system and the impact categories considered as outputs. We then need more information on the models involved in the CED calculation for a better knowledge of the influence of the photovoltaic electricity variation on the CED variation. The comparison of scenarios shows that a systemic global policy is far more efficient than individual initiatives willing to auto-produce electricity.

The importance of the type of allocation models is pointed out when focusing on LCAs of products. The input parameters used for the allocation coefficients (mass ratios, market prices ...) have no influence, which means that their variability is less influential than the allocation method itself. This result is highly dependent on the present case study. However, some previous studies have already underlined its influence (Sayagh et al., 2010). The results may be different particularly if the product price volatility is high, because it introduces greater uncertainty.

Finally, the present study demonstrates that save for CED and climate change, the technological options depend on the farmer's decisions during hemp crop production through the influence of parameters like the characteristics of farm equipment, the crop production scenario, the quantity of nitrogen fertilizer or the type of mineral fertilizer.

A common strategy for a joint action with farming and industrial actors would allow for a more effective impact reduction than actions taken by the industrial actor alone. However, in practice, such a scenario would be difficult to implement.

\subsection{Methodological discussion}

In the perspective of the industrial actor, two products are produced simultaneously on a single production site: hemp concrete and insulation board.

In a life cycle perspective, the building actors will consider the environmental performances for each product separately ones and this separation is introduced in our model using partitional allocation.

However, the industrial actor taken in isolation can consider reducing environmental impacts of the joint production. In this perspective, the environmental performance of the gate-to-gate foreground sub-system, considered globally and independently from the allocation between output products, is also interesting, because it provides the effective possible improvement at the industrial site level. This is an environmental management perspective in a life cycle context.

From this perspective, both products can be considered at the level of the physical relationship between quantities of each coproduct produced simultaneously rather than at the level of comparable functional units between products. In that case, for $1 \mathrm{~m}^{2}$ of hemp concrete, approximately $3 \mathrm{~m}^{2}$ of insulation boards are simultaneously produced. The same SA approach was conducted for identifying action levers of the industrial production site, without an allocation within the industrial actor's sub-system. Results are not presented here, as they did not provide very different results: the individual influence of previously identified action levers was reinforced compared to influences of interactions, confirming the interaction influence of the allocation method.

\section{Conclusion}

The aim of the systematic method proposed here is to identify and quantify the environmental consequences of the different action possibilities available within a two-actor system with industrial transformation of insulation boards and hemp concrete considered as a foreground system. As environmental management issues, the industrial actor can decrease binder addition (polyester and hydraulic lime) in the products as well as electricity consumption to reduce climate change and cumulative energy demand impacts. The uncertainty regarding these possible reductions is mainly related to the chosen allocation method and to the field emission factors for crop production (Andrianandraina et al., 2015). However, in a life cycle perspective, reducing binder content could affect the thermal and mechanical properties of the materials thus reducing or cancelling the environmental improvements during the service life of the insulators. This phenomenon constitutes a possible antagonistic effect between the industrial actor and both construction and user actors of the next step of the life cycle. More work needs to be carried out in order to determine whether such a reduction is still relevant when introducing the use phase in the life cycle. Additional actions, not tested here, could be the use of other binder types having a lower environmental impact.

The reduction of the electricity consumption is the only sure action among the possibilities for the industrial actor. However, a deeper analysis of the transformation processes would be required to confirm the feasibility of such a reduction. The model proposed for the industrial production site is limited in terms of parameters. The results, and more broadly, the method, are linked to the level of details of the foreground system modelling. Introducing on-site local electricity production using photovoltaic panels does not reveal any influence since it would require an enormous surface area of panels.

For the other environmental impacts, the farming actor remains the most influent; this observation, however, needs to be confirmed by the study of the next steps of life cycle.

Finally, we observe that no possible individual action is virtually at the disposal of the industrial actor. Only the combination of actions from both the farming and industrial actors could be effective.

This study is indeed the first to analyse individual and joint action levers of different actors in a life cycle assessment. The proposed method can be used to determine some synergistic and antagonistic relationships between different actors and parameters within a life cycle context. Some research prospects have to be explored in order to reduce calculation costs like model reduction (Lacirignola et al., 2014).

By testing modelling assumptions made solely by LCA experts, we introduce a specific actor, which is not an economic actor, but a methodological actor. This approach thus includes scientific choices and possible resulting subjectivity within the variability of results, being closer to a post-normal methodology (Macombe, 2013) than to a classical scientific method.

\section{Acknowledgments}

The authors would like to acknowledge the French Environment and Energy management Agency (ADEME) and the Region Pays de la Loire, France, for their financial support.

Funds for the research and education chair of civil engineering and eco-construction were provided by the Chamber of Trade and Industry of Nantes and Saint-Nazaire cities, the CARENE (urban agglomeration of Saint-Nazaire), Charier, Architectes Ingénieurs Associés, Vinci construction, the Regional Federation of Buildings, and the Regional Federation of Public Works. The authors would like to thank all these partners for their collaboration. 
The co-authors are grateful that their research networks, EcoSD (the French network for eco-design of sustainable systems www. ecosd.fr) and AgorACV (the regional network of LCA scientists in the Bretagne and Pays de la Loire regions), which have allowed them to advance their knowledge and expertise.

\section{Appendix A. Supplementary data}

Supplementary data related to this article can be found at http:// dx.doi.org/10.1016/j.jclepro.2016.10.069.

\section{References}

Andrianandraina, Ventura, A., Senga Kiessé, T., Cazacliu, B., Idir, R., van der Werf, H.M.G., 2015. Sensitivity analysis of environmental process modeling in a life cycle context: a case study of hemp crop production. J. Ind. Ecol. http:// dx.doi.org/10.1111/jiec.12228 n/a-n/a.

Basset-Mens, C., Kelliher, F.M., Ledgard, S., Cox, N., 2009. Uncertainty of global warming potential for milk production on a New Zealand farm and implications for decision making. Int. J. Life Cycle Assess, 14, 630-638.

Boutin, M.-P., Flamin, C., Quinton, S., Gosse, G., 2006. Etude des caractéristiques environnementales du chanvre par l'analyse de son cycle de vie. Technical report INRA. France, Lille.

Cérézo, V., 2005. Propriétés mécaniques, thermiques et acoustiques d’un matériau à base de particules végétales: approche expérimentale et modélisation théorique. Institut National des Sciences Appliquées de Lyon.

Chen, X. Corson, M.S., 2014. Influence of emission-factor uncertainty and farmcharacteristic variability in LCA estimates of environmental impacts of French dairy farms. J. Clean. Prod. 81, 150-157.

Collet, F., Chamoin, J., Pretot, S., Lanos, C., 2013. Comparison of the hygric behaviour of three hemp concretes. Energy Build. 62, 294-303.

Cowell, S.J., Fairman, R., Lofstedt, R.E., 2002. Use of risk assessment and life cycle assessment in decision making: a common policy research agenda. Risk Anal. 22, 879-894.

Cucurachi, S., Borgonovo, E., Hiejungs, R., 2016. A protocol for the global sensitivity analysis of impact assessment models in life cycle assessment. Risk Anal. 36 http://dx.doi.org/10.111/risa.12443.

Evrard, A., Herde, A.D., 2010. Hygrothermal performance of lime-hemp wall assemblies. J. Build. Phys. 34, 5-25. http://dx.doi.org/10.1177/1744259109355730.

Finnveden, G., Ekvall, T., 1998. Life-cycle assessment as a decision-support tool the case of recycling vs. incineration of paper. Resour. Conserv. Recycl. 24, 235-256.

Frischknecht, R., 1998. Life Cycle Inventory Analysis for Decision-making: Scopedependent Inventory System Models and Context-specific Joint Product Allocation. Swiss Federal Institute of Technology, Zurich.

Garcia Sanchez, D., Laccarière, B., Musy, M., Bourges, B., 2013. Application of sensitivity analysis in building energy simulations: combining first- and second-order elementary effects methods. Energy Build. 68 (Part C), 741-750.
Hamby, D.M., 1994. A review of techniques for parameter sensitivity analysis of environmental models. Environ. Monit. Assess. 32, 135-154.

Hofstetter, P., Baumgartner, T., Scholz, R.W., 2000. Modelling the value sphere and the ecosphere: integrating the decision makers' perspectives into LCA. Int. J. Life Cycle Assess. 5, 161-175.

JRC, Commision European, 2010. International Reference Life Cycle Data System (ILCD) Handbook - general Guide for Life Cycle Assessment-detailed Guidance. 2010. EUR 24708 EN. European Commission, Joint Research Centre. Institute for Environment and Sustainability. Publications Office of the European Union, Luxembourg.

Lacirignola, M., Meany, B.H., Padey, P., Blanc, I., 2014. A simplified model for the estimation of life-cycle greenhouse gas emissions of enhanced geotherma systems. Geotherm. Energy 2, 1-19.

Macombe, C., 2013. Should life cycle-based methods fit in post-normal science to improve robustness?. In: SETAC. Presented at the LCA Case Study, November 14th, Rome, Italy.

Miettinen, P., Hämäläinen, R.P., 1997. How to benefit from decision analysis in environmental life cycle assessment (LCA). Eur. J. Oper. Res. 102, 279-294.

Morris, M.D., 1991. Factorial sampling plans for preliminary computational experiments. Technometrics 33, 161-174.

Padey, P., Girard, R., Le Boulch, D., Blanc, I., 2014. From LCAs to simplified models : a generic methodology applied to wind power electricity. Environ. Sci. Technol $47,1231-1238$

Sayagh, S., Ventura, A., Hoang, T., Francois, D., Jullien, A., 2010. Sensitivity of the LCA allocation procedure for BFS recycled into pavement structures. Resour. Conserv. Recycl. 54, 348-358.

Senga Kiessé, T., Ventura, A., Andrianandraina, Idir, R., van der Werf, H., 2013. Action-oriented Life Cycle Assessment: case study of hemp based insulation products for buildings. In: In the 19th SETAC LCA Case Study Symposium, Rome, Italy, 11-13 November 2013.

Seppälä, J., Basson, L., Norris, G.A., 2001. Decision analysis frameworks for life-cycle impact assessment. J. Ind. Ecol. 5, 45-68.

Sobol, I.M., 2001. Global sensitivity indices for nonlinear mathematical models and their Monte Carlo estimates. Math. Comput. Simul. 55, 271-280.

Tillman, A.-M., Ekvall, T., Baumann, H., Rydberg, T., 1994. Choice of system boundaries in life cycle assessment. J. Clean. Prod. 2, 21-29.

Tillman, A.-M., 2000. Significance of decision-making for LCA methodology. Environ. Impact Assess. Rev. 20 (1), 113-123.

Tran Le, A.D., 2010. Etude des transferts hygrothermiques dans le béton de chanvre et leur application au bâtiment. Thèse de doctorat. Université de Reims, Champagne-Ardenne, p. 209.

Tran Le, A.D., Maalouf, C., Mai, T.H., Wurtz, E., Collet, F., 2010. Transient hygrothermal behaviour of a hemp concrete building envelope. Energy Build. 42 1797-1806.

Van der Werf, H.M.G., Harsveld van der Veen, J.E., Bouma, A.T.M., ten Cate, M., 1994 Quality of hemp (Cannabis sativa L.) stems as a raw material for paper. Ind Crops Prod. 2, 219-227.

Ventura, A. Andrianandraina, van der Werf, H.G. Idir R, 2013. Action-oriented Life Cycle Assessment: example on hemp-based construction materials. In: 7th International Society for Industrial Ecology (ISIE), June 25-28, Ulsan, Korea. 